\title{
The meaning of work after spinal cord injury: a scoping review
}

\author{
Mohammad Mosayed Ullah $\mathbb{D}^{1} \cdot$ Ellie Fossey ${ }^{2,3} \cdot$ Rwth Stuckey $^{4}$
}

Received: 16 January 2017 / Revised: 21 August 2017 / Accepted: 21 August 2017 / Published online: 23 October 2017

(C) International Spinal Cord Society 2018

\begin{abstract}
Study design Scoping review.
\end{abstract}

Objectives To explore the meaning of work after spinal cord injury (SCI) in existing literature.

Methods Arksey and O'Malley's widely used methodological framework for scoping reviews was used to guide this review. Studies involving adults with SCI, conducted using qualitative methods, and published in peer reviewed literature were identified based on key terms and searches in three databases (CINAHL, MEDLINE, PsycINFO). Further search steps included checking citations in identified articles and citation tracking for other relevant articles and reviews. Reported qualitative data were then thematically analysed to generate themes.

Results Twelve studies were included. Three themes were identified across these studies that describe the meanings of work after spinal cord injury: re-developing a sense of self, re-establishing place in the community and regaining economic selfsufficiency.

Conclusions The varied meanings of work after SCI identified in this review may be used in rehabilitation programs to explore ideas about work, the types of work they wish to pursue, and the ways in which work may be meaningful for people with SCI, so as to identify individually and contextually relevant work. Taking account of meaning in ICF based models of work participation could enhance patient-centred approaches in SCI rehabilitation.

\section{Introduction}

Epidemiological studies globally show that spinal cord injury (SCI) most commonly occurs among people of $15-40$ years of age [1-3], which corresponds with either their vocational development or being of working age [4]. When

Mohammad Mosayed Ullah

mosayedbd@gmail.com

1 Department of Occupational Therapy, School of Allied Health, College of Science, Health and Engineering, La Trobe University, Melbourne, VIC 3086, Australia

2 Department of Occupational Therapy, School of Primary Health Care, Monash University, Peninsula Campus, Frankston, VIC 3199, Australia

3 Living with Disability Research Centre, School of Allied Health, College of Science, Health and Engineering, La Trobe University, Melbourne, VIC 3086, Australia

4 Centre for Ergonomics and Human Factors, School of Psychology and Public Health, College of Science, Health and Engineering, La Trobe University, Melbourne, VIC 3086, Australia affected persons remain out of work, SCI impacts negatively on life satisfaction [5] and economically both at personal and societal levels [6]. Work and employment are considered important means of participation and integration in society for adults with SCI [7, 8]; returning to work can also improve quality of life and longevity $[4,5]$. However, return to work rates following a disability like SCI are estimated to vary from 11.5 to $74 \%$ internationally $[4,9,10]$, with differences being identified as due to many factors including variation in injury compensation, health care and support systems, legislation, as well as methodological and measurement issues $[9,10]$.

Previous research also identifies that entering the workforce after SCI is complex, may take considerable time to achieve, and is influenced by many interrelated factors. These factors include individual needs, expectations, time since injury, available supports and resources, type of employment, employer role, and individual attributes such as age, educational level, injury severity, ethnicity and previous work experience $[4,7,8,10,11]$. Previous studies also show that psychosocial factors strongly influence return to work success after injury, including affective experience 
or feelings, individual's thoughts and beliefs about quality of life, life satisfaction, and adjustment to sustaining SCI [5,11-14]. Further, the most frequently reported barriers to employment include transportation, physical limitations, insufficient education or vocational training, architectural barriers, financial disincentives and attitudes of employers [9]. Most of these studies have been predominantly quantitative in nature, yet people often also experience changed perspectives of their lives, activities and surroundings following SCI [15]. The experience and the meaning of disability can also be altered when the consequences of an impairment are changed through engagement in valued occupations $[16,17]$. This suggests the 'meaning of work' may be an important subjective issue that impacts return to work success after SCI, making it important to understand from the perspectives of people with SCI themselves.

A scoping review in 2014 explored what work means to people with major health conditions and disabilities [18]. Its finding indicated that while people remain motivated to return to work, the meaning of work may be changed in the context of disability. This review included 52 studies involving participants with widely varying conditions (e.g., cancer, brain injury, mental illness, and intellectual disability). While useful, its findings relating to what work means following SCI are limited given only 3 of the 52 studies focused on people with SCI. An earlier review of qualitative studies investigating quality of life after SCI [15] identified engagement in personally meaningful occupation as one of ten dimensions that contributed to experiencing a life worth living. While demonstrating the value of reviewing qualitative studies to better understand experiences of work and disability, neither review focused specifically on the meaning of work participation from the perspective of people with SCI. This suggests a more focused review of studies relevant to this population would be useful to map what is known about the meaning of work following SCI. In turn, this could assist rehabilitation professionals in practice to enable individuals with SCI identify personally meaningful work opportunities, and consider the 'meaning of work' as a factor in their return to work success. With the aim to better understand the meaning of work participation from the perspectives of people with SCI, this paper reports a scoping review of research about the meaning of work for adults following SCI.

\section{Methods}

A scoping review approach was chosen to review and describe research findings about the meaning of work after SCI since it facilitates the systematic mapping of current research, and the identification of gaps in existing literature [19]. Arksey and O'Malley [19] described a scoping review methodology with five main stages used to guide this review: identifying the research question, searching for relevant studies, study selection, charting the data and then collating, summarising and reporting the results.

\section{Stage 1: Identifying the research question}

The identified scoping review question was "What is known about the meaning of work after SCI?" Three key concepts were identified from the review question: 'spinal cord injury', 'work' and 'meaning'.

\section{Stage 2: Identifying the relevant studies}

Suitable terms were identified in the databases, to search for relevant studies. The search terms chosen for the above key concepts were "Spinal Cord Injur*" OR "Spinal cord lesion*" OR "Spinal Cord Disease*" OR Paraplegi* OR Tetraplegi* for spinal cord injury; Work* OR Employment OR Job* OR Vocation* OR Occupation* for work; Meaning* OR Identity OR Perception OR Value OR Life Purpose for meaning. Using these search terms, three electronic database searches were conducted to identify studies related to the scoping review question. These databases, CINAHL, MEDLINE 1996- (Ovid) and PsycINFO 1987- (Ovid), were considered the most relevant to this research area. The initial database searching was undertaken in 2014 and the search re-run in October 2015. The searches used the limiters: journal type (Peer Reviewed Journal), age range (adolescent and above), Language (English), and timeframe (last 20 years). In the second step, reference list checking, citation tracking of related articles and tracking studies cited in recent reviews $[4,9,10,13,15,18,20]$ were also completed. These search processes aimed to identify studies involving participants aged 18 years or older; conducted using qualitative or mixed methodologies, and published in peer reviewed journals. These criteria were justified as follows: (a) studies using qualitative methodology or mixed methods were included as qualitative studies are the most likely to describe findings about the meaning of work from participants' own perspectives; (b) studies involving people younger than 18 years of age were excluded since they are less likely to be in the workforce; and (c) only peer reviewed articles were included to focus on research evidence. Therefore, grey literature was not searched, and in the case of studies of mixed methods studies, the qualitative part of data collection, analysis and results were considered for the review.

\section{Stage 3: Study selection}

All studies identified through the database searches were exported to Endnote bibliographic software with abstracts 


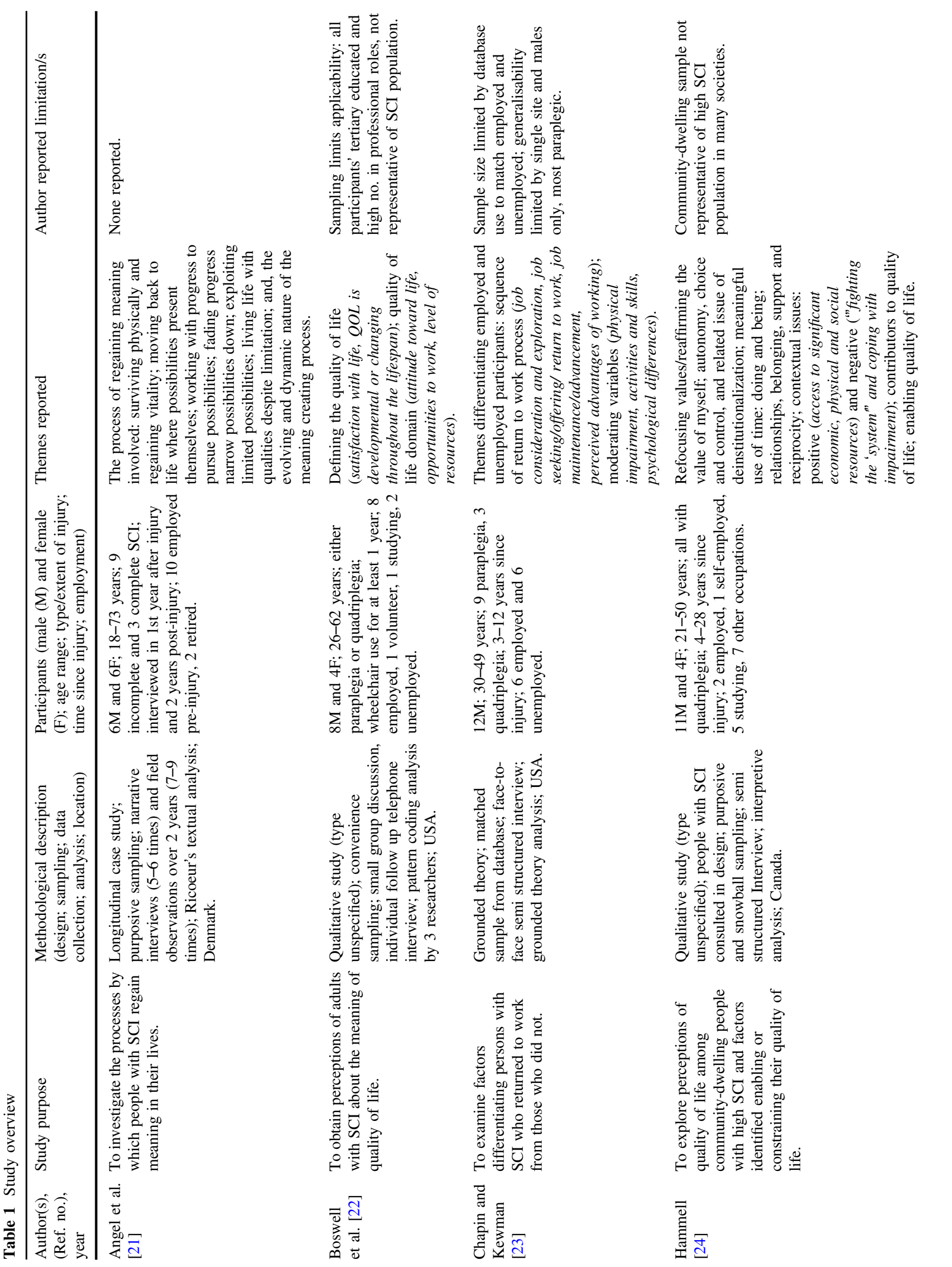



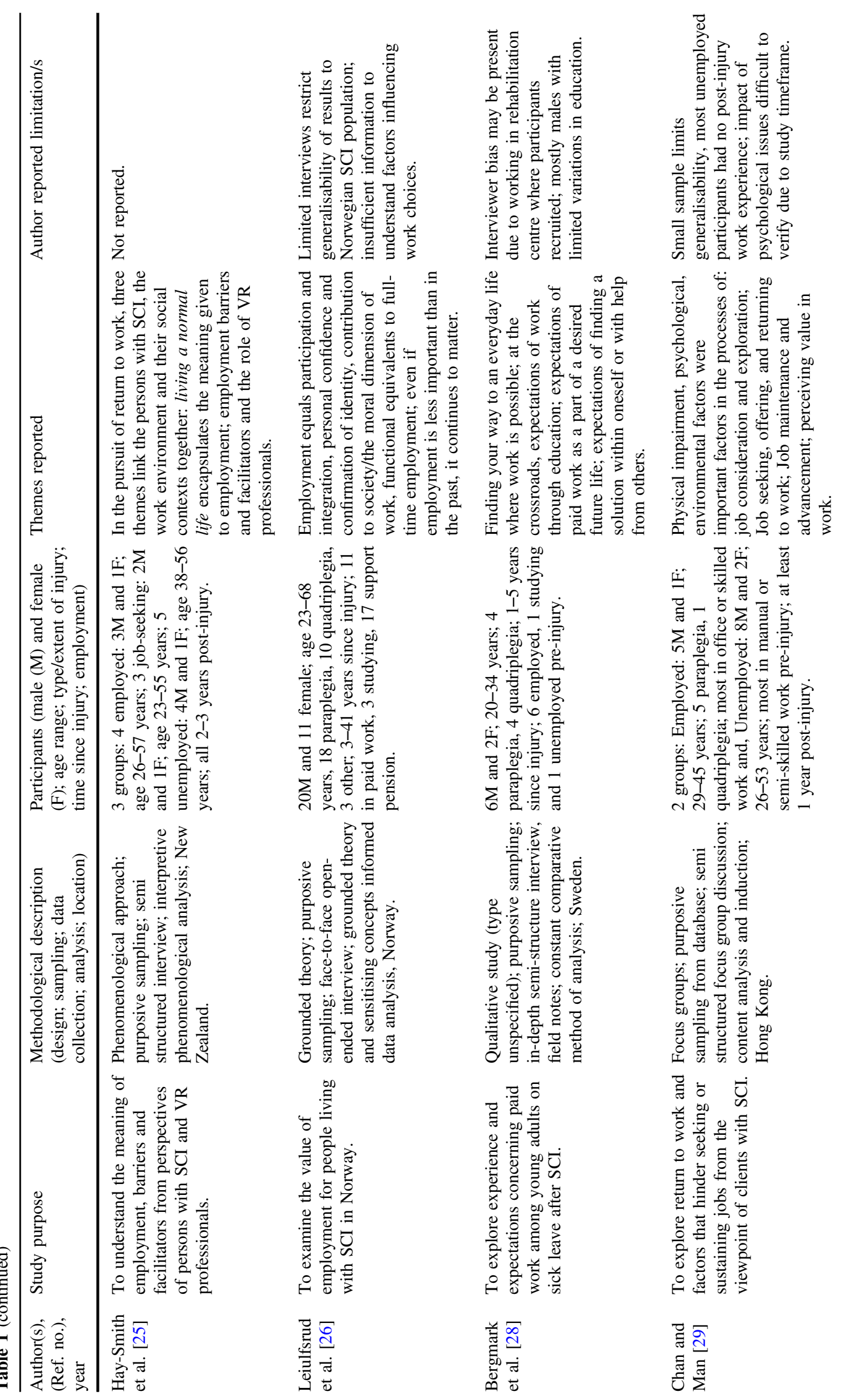

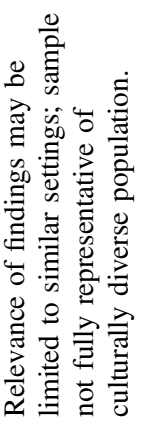

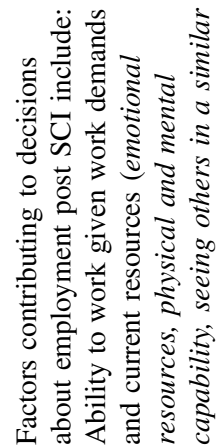

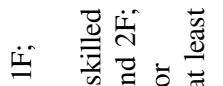

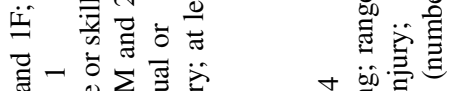

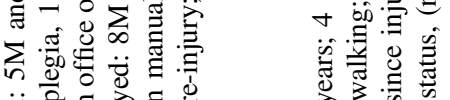

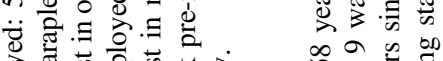

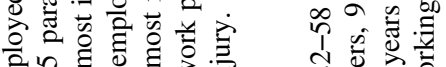

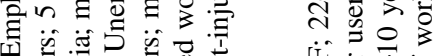

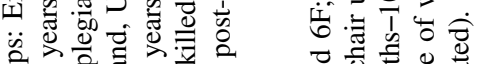

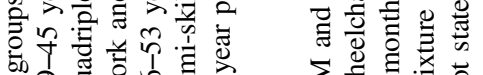

๙

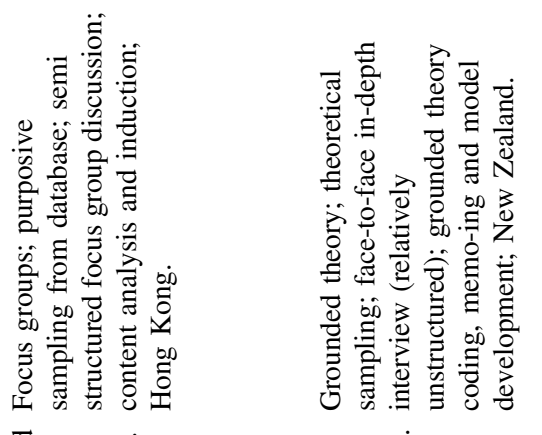

䓂

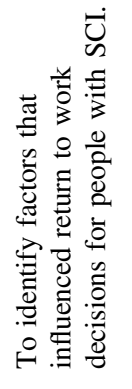

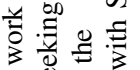

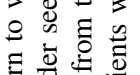

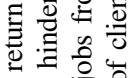

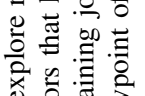

खิ

高 $\overline{\mathrm{d}}$

ฮี ฮี

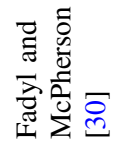




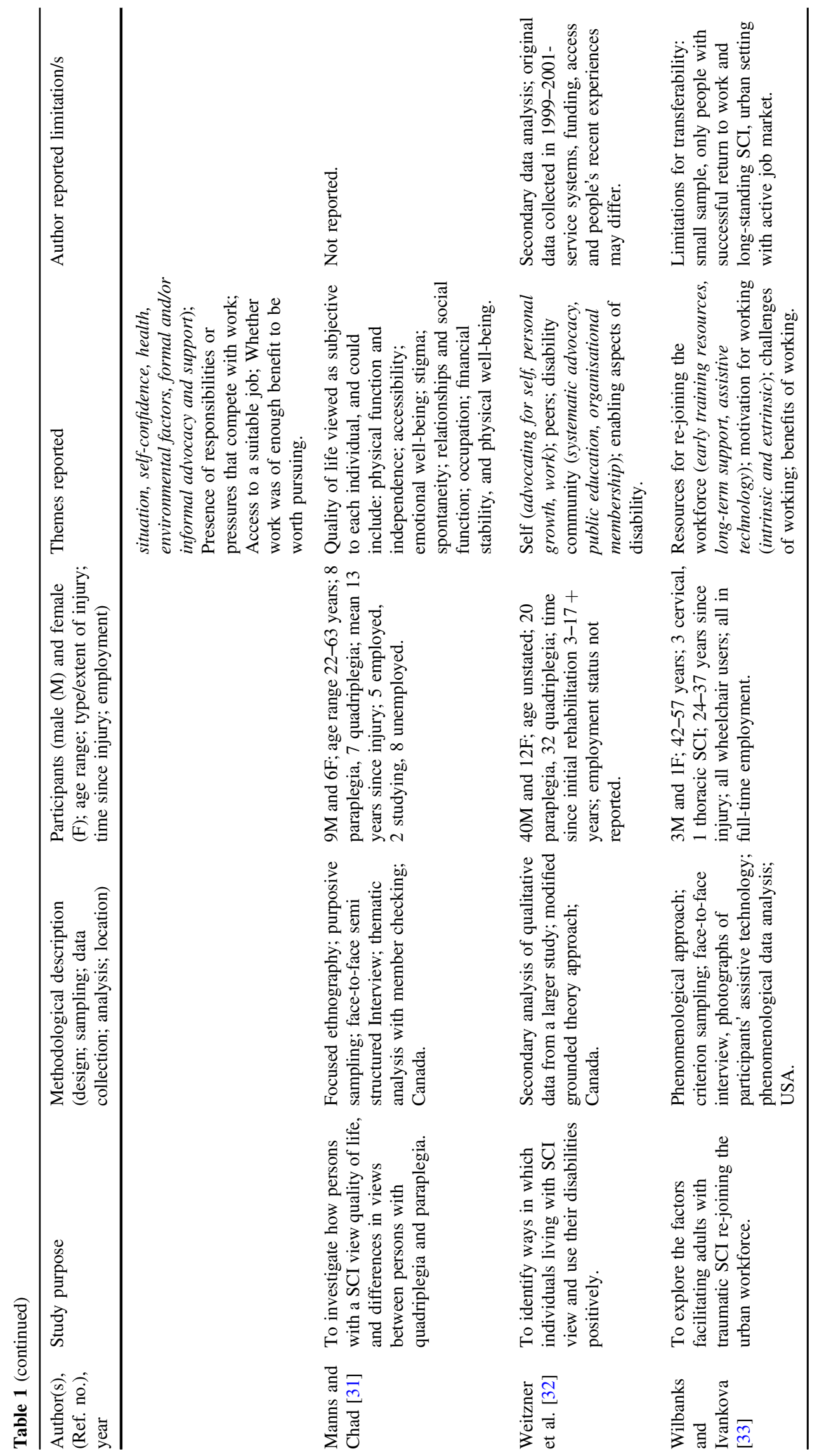




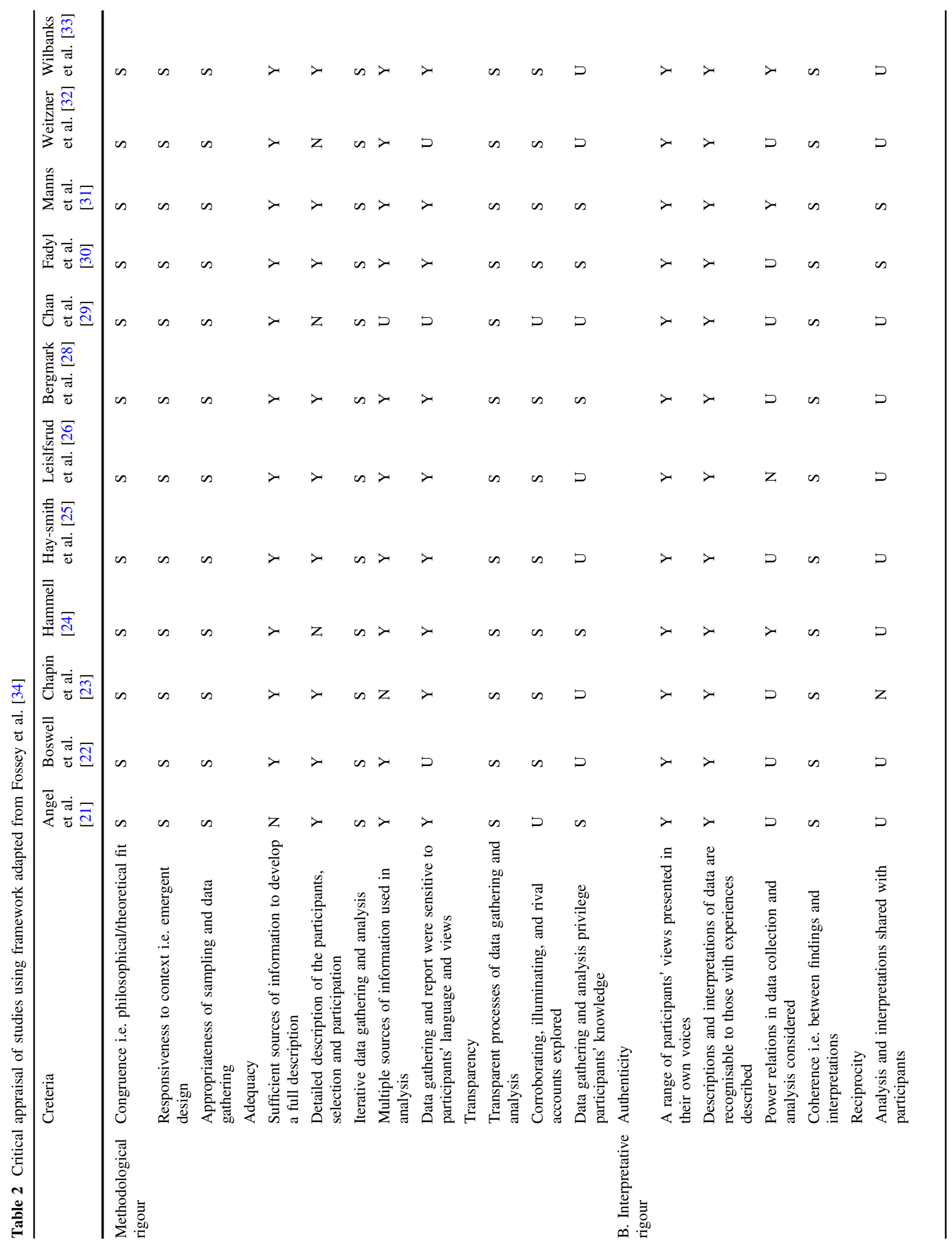




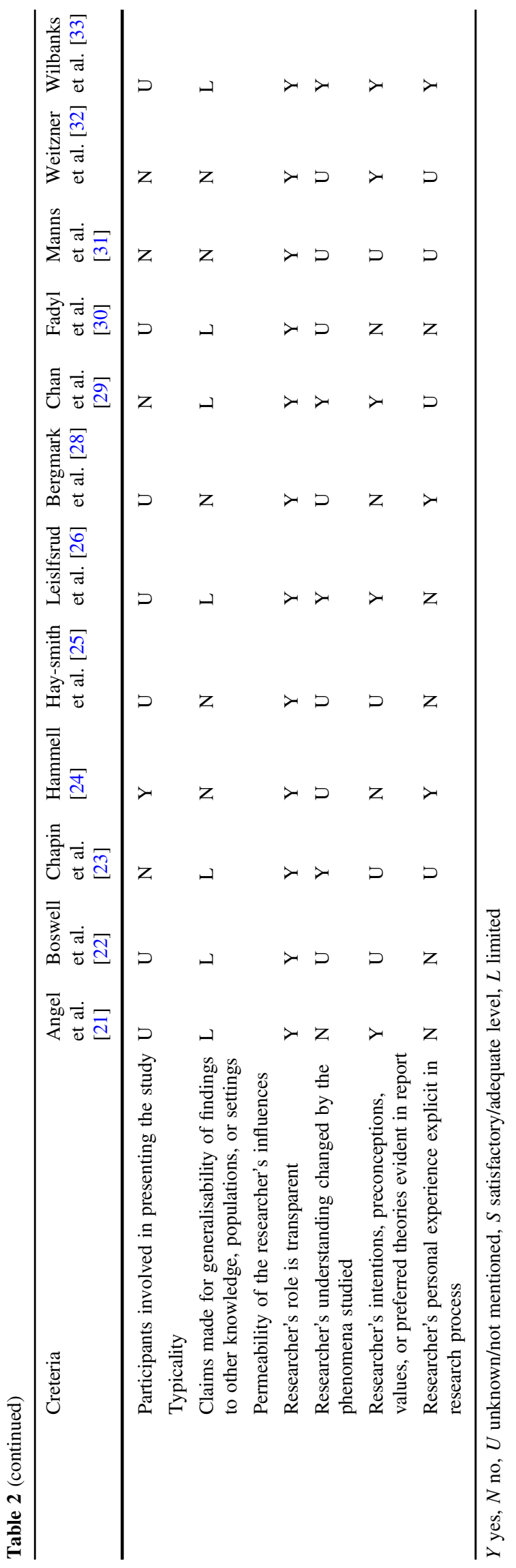

and references. The first author manually removed duplicates from Endnote, leaving 283 studies to check for matching with the inclusion criteria. These 283 articles were then exported to a Microsoft word document for all three authors to read the titles and abstracts. After initial screening, 16 relevant studies were identified based on the study inclusion criteria. The full texts of each of these 16 articles were then thoroughly read, and 7 studies were selected based on their content being directly related to the meaning of work after SCI [21-27]. Despite meeting the initial selection criteria, eight articles were rejected as they did not include content relevant to the meaning of work; one more study was then excluded due to lack of participant quotations [27]. Through citation tracking (online), 6 more studies were identified that met the inclusion criteria [28-33]. All three authors reviewed and agreed upon the final selection of these 12 studies.

\section{Stage 4: Charting data}

Charting the data was completed in three stages. First, data were extracted from each paper for critical appraisal to understand and evaluate the quality of the reported research. The first author extracted key information about each study, using the following headings: Author(s), year; study purpose; methodological description (design, sampling, data collection, analysis, and location); participant description (male, female; age range (years)/average; time since injury; level and extent of injury; unemployed, employed; and setting); overall findings; list of stated themes and author stated limitations. A summary of the key information extracted about each study is presented in Table 1.

Secondly, the first author then used the guidelines described by Fossey and colleagues [34] to appraise the methodological and interpretive rigour of each study, as presented in Table 2 and summarised in the Results section. Despite variation in their quality, none were excluded on the basis of quality since all met inclusion criteria and reported sufficient data related to the meaning of work in quotations that could be used to identify themes.

Thirdly, the findings/results sections of all the selected studies were reviewed several times to understand the content focused on the meaning of work and quotations from participants. These quotations were then charted in a separate document for the final stage of collating and reporting results described below. While the first author developed the data extraction charts and undertook the data extraction and quality appraisal for each study, the three authors held regular meetings to review the data and make decisions at each step and to ensure the accuracy of the data extracted and summarised in Tables 1-4. 


\section{Stage 5: Collating, summarising and reporting the results}

After the first round of data extraction, the quotations were reviewed multiple times by the authors, and grouped into three major themes and five categories based on their derived meaning (See Fig. 1). Each theme represents meanings expressed about work after SCI in reported quotations from across the 12 included studies. This process was conducted through a series of discussions amongst the authors until a consensus was reached.

\section{Results}

\section{Study content overview}

The studies included in this scoping review were conducted in 7 countries, with most study participants recruited using purposive sampling, while one study used theoretical sampling [30], and one used snowballing [24]. Across the 12 studies, the majority of study participants $(70 \%)$ were men, but most studies included samples with men and women, differing types of paralysis and varying employment status. The exceptions were four studies that focused on men only [23], participants with tetraplegia only [24], only employed people with SCI [33], or only those who were unemployed [28]. Limited information was provided about participant characteristics or recruitment in three studies [21, 30, 32].

Six studies [21, 24, 25, 28, 30, 33] specifically mentioned the nature of injury was traumatic, and one study [26] described a mixed group of participants: 3 with nontraumatic SCI and 28 with SCI resulting from trauma. The remaining 5 studies implied injury was the origin of participants' SCI given their use of the term 'pre-injury' and no mention of disease-related causes. No study was excluded based on upper age limit or retirement age as this does not apply to many contemporary workers [35]. Participants ages ranged from 18 years to 73 where stated. One study included a participant over 70, and 3 studies included participants in their 60s. Time since injury ranged from 1-48 years except one study which included participants 2 months after injury. Table 1 provides a study overview.

\section{Study quality appraisal}

The reviewed studies were of variable quality, as shown in Table 2. All 12 studies reported research consistent with their chosen methodology, and were developed and adapted to respond to real-life situations within the social settings in which they were conducted. All adequately described the participant selection criteria, process of sampling, data

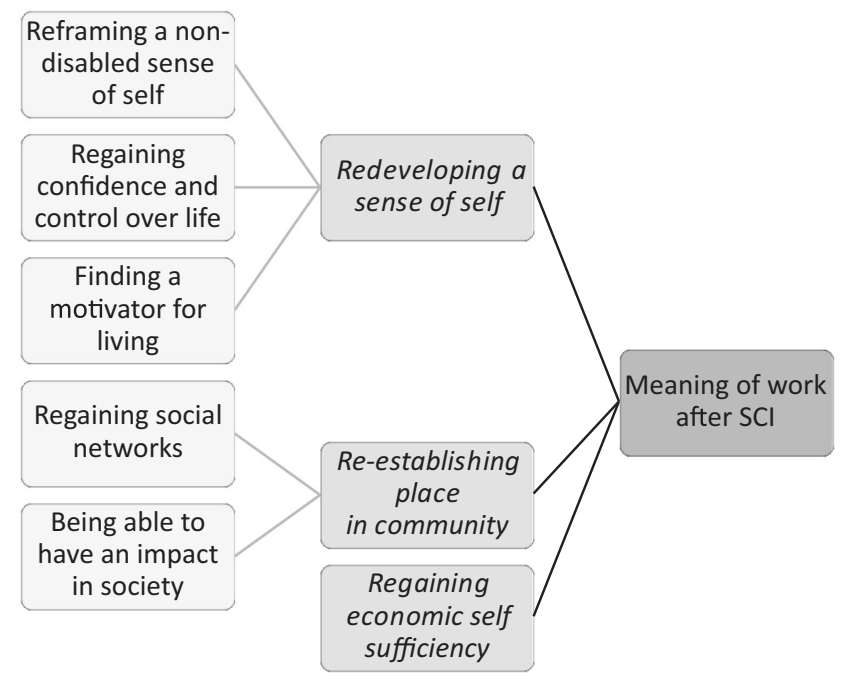

Fig. 1 Major themes related to meaning of work

collection and analysis. All but two studies [22, 29] used face to face interview data collection. All except two $[23,29]$ reported use of multiple data collection sources for analysis. All studies clearly described both the analysis processes and author participation in the generation of results, including how differences were managed and consensus reached. Only one study used an external auditor to review findings and interpretations [31], and three studies considered the power relations between the participants and authors during data collection and analysis [24, 31, 33]. While the researchers' role in the interpretive process was clear in all the studies, three studies explicitly described changes in authors' understanding or preconceptions of the phenomena studied [26, 29, 33]. Two studies reported use of member checking to increase reciprocity and interpretive rigour: Manns and Chad [31] sent their preliminary themes to the participants for checking, then revised them; and Fadyl and McPherson [30] used presentations and meetings to obtain stakeholder feedback on their findings.

\section{Themes}

Three major themes related to the meaning of work are presented in Fig. 1. Each theme is briefly described with illustrative quotations taken from the reported findings.

\section{Redeveloping a sense of self}

Work participation after SCI was described in a variety of ways by people with SCI related to how they viewed themselves. These include that work is a means of participation, reinventing oneself, mental stimulation, gaining a sense of purpose, self-satisfaction and personal growth. These personal meanings for return to work after SCI were 


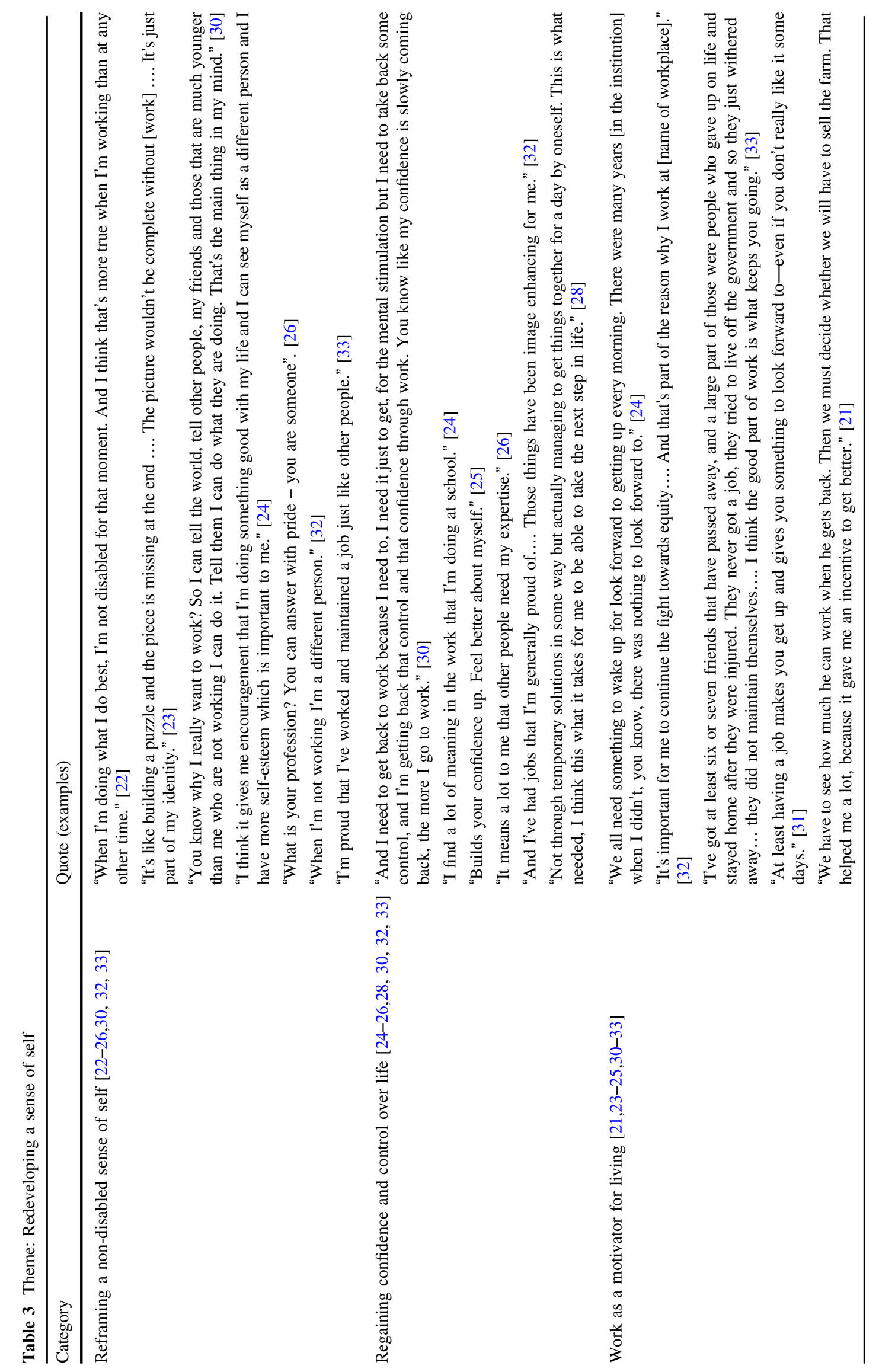


categorised as related to three distinct issues: reframing a non-disabled sense of self, or the possibility of seeing oneself as more than a disabled person, with functions and capacities beyond their disability; regaining confidence and control over life, that is developing a sense of being competent to manage oneself again and work as a motivator for living, or something to look forward to, keep people going and give a sense of purpose to life. Illustrative quotes are presented in Table 3.

\section{Re-establishing place in community}

Work was described as an important marker of "being part of society" [25], a means for people with SCI to re-establish their place in the community. For people with SCI who participated in the reviewed studies, work had two social meanings. Firstly, work provided an opportunity to get out amongst people again and into a social world beyond one's home, so that it served to reduce the potential for social isolation. Secondly, through work, participants across a number of the studies emphasised being able to contribute or to give back to society in ways that were not only meaningful to them but also valued by others. These meanings of work are further illustrated by the quotations in Table 4.

\section{Regaining economic self sufficiency}

Re-joining work after injury was seen as a means of becoming self-sufficient, and making an economic contribution by people with SCI who participated in the reviewed studies. For some participants, returning to work was an economic necessity, or earning one's own money represented a more respectful and respected way of living than relying on social welfare for income support. Some participants also expressed concerns about the potential impact of work on their disability-related social welfare benefits, and about not being able to earn enough to support themselves (Table 4).

\section{Discussion}

Psychosocial factors are acknowledged as important influences on employment outcomes following SCI [4, 13], with the meaning derived from work being one factor that might be altered following disability [18]. By focusing on the meanings of work from the perspectives of people with SCI reported in 12 qualitative studies, this review sought to enhance understanding of the aspects of meaning that are important in work participation after SCI. In particular, the meanings of work appear to act as a 'motivator' to inspire and direct one's pursuit of work participation after SCI, and to seek a valued way of life in one's community. The redevelopment of these meanings in work for people after SCI involves integrating inner experiences of themselves and their capacities, with the outer possibilities for working $[21,30]$. Both are reflected in the three themes of meaning in work identified in this scoping review: redeveloping $a$ sense of self, re-establishing place in community, and regaining economic self-sufficiency, each of which is briefly discussed.

Across the 12 studies reviewed, the majority of study participants described work as personally important for their sense of self. Their work identity overrode their sense of being disabled and they felt pride in seeing themselves as workers, so that work gave them a sense of taking control of their lives, and a sense of purpose and routines in daily life, helping motivate them for the future. While this aligns broadly with themes across disability groups for whom work is viewed as important as a source of identity [18], the findings of this scoping review add depth to our understanding of how persons with SCI re-develop their sense of self. Specifically, regaining confidence and control in life, and work as a motivator for living and reframing disability appear important. As work offers a means of building confidence in life after injury [22, 28] and is associated with improved life satisfaction and quality of life [13], the emphasis placed on the re-construction of an identity as a worker by participants across a number of studies in this review (e.g. 24, 25) endorses the importance of opportunities for people with SCI to experience work and to develop their own sense of work readiness and job options, during and beyond rehabilitation [23, 28]. This also supports the argument for earlier or timely access to vocational interventions after injury [30].

This review also found that work matters as an important outward indicator of fitting in socially, and is valued not only as a means of connecting with other people and social environments [25, 26, 33], but also of engaging in reciprocal relationships and contributing to society in a way that is respected by others [24, 25, 28, 29]. Further this review adds to previous knowledge in highlighting that work holds meaning as a way to re-establish one's place in the community not only through social connections with others, but also as an active agent in making an impact within society. While work is seen as a means to connect with others, the reverse is also the case: social supports and networks, including peers, serve to connect people with their work potential and possibilities after SCI [27, 29, 30, 32]. This suggests rehabilitation providers might do more to support job exploration and maximise consideration of potential work options by fostering connections between people with SCI through active involvement of peer mentors and networks - ideas that are particularly relevant to job-seekers with spinal cord injury [30]. 


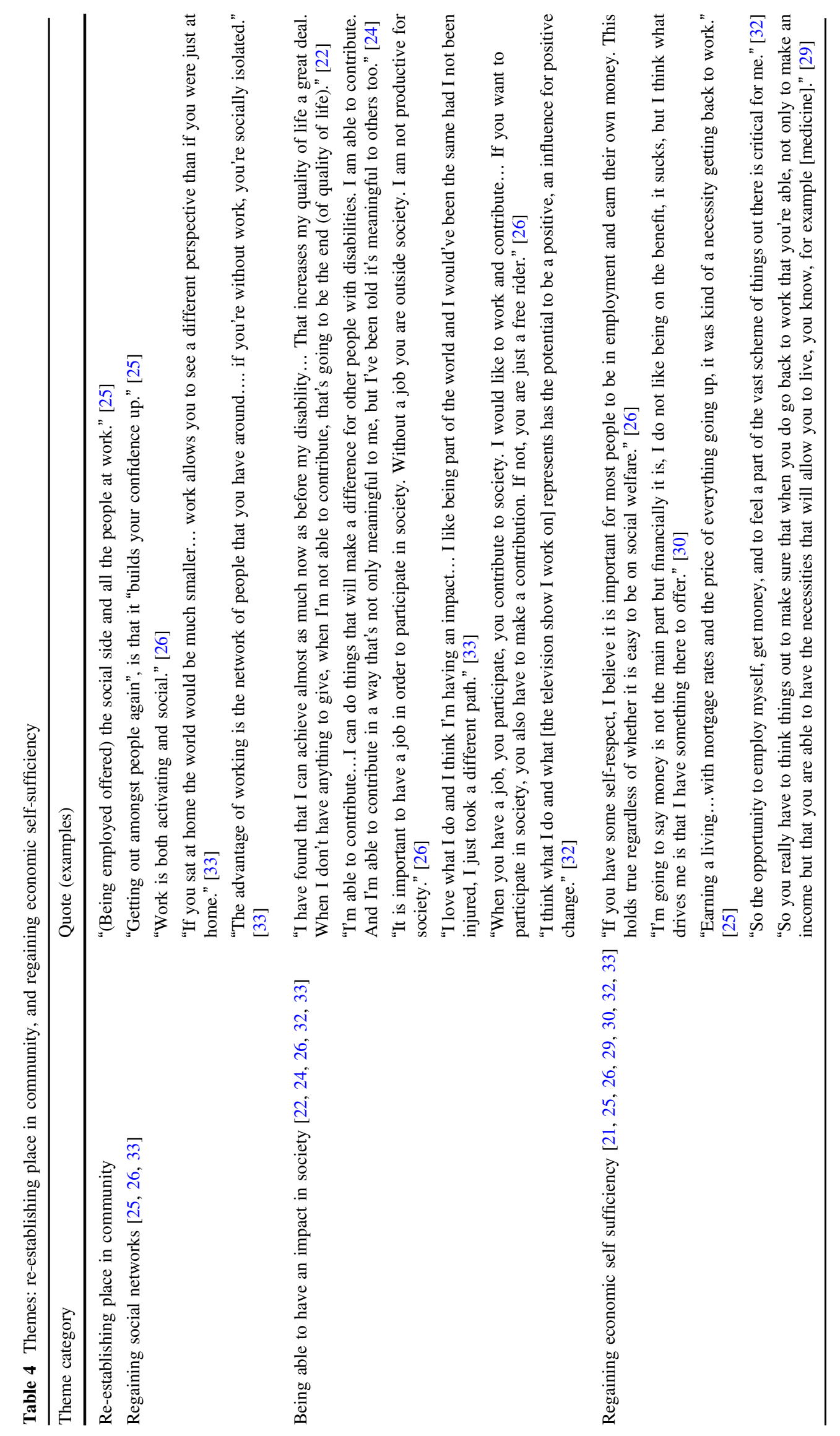


Paid work is a major source of income, so it is unsurprising that regaining economic self-sufficiency is one of the meanings ascribed to work by participants in the reviewed studies. More specifically, engaging in the workforce was seen to bring not only immediate monetary benefit but also a sense of self-respect and the possibility of becoming economically self-sufficient. This review also identified many contextual factors as contributing to whether or not work held the possibility for regaining a sense self-sufficiency for persons with SCI, including whether they had access to suitable work to earn sufficient income to support themselves [30], welfare policy issues, financial hardship due to unemployment, and inaccessible transport and environments. Hence, context needs to be accounted for when considering the relative importance of economic selfsufficiency in comparison to other meanings of work for individuals. For instance, in a Swiss study of determinants and consequences of having paid work after SCI, social reasons were among the most frequently reported for working after SCI [36]. Yet, this and the reviewed studies all being conducted in relatively high-income countries, so that the meanings of work participation in lower-income countries, particularly in relation to achieving a sense of self-sufficiency, may differ from those reported here.

Overall, the scoping review findings have provided detailed information for understanding the meaning of work from the perspectives of people with SCI. Based on a review of factors contributing to work-ability for injured workers, Fadyl et al. [37] used the ICF framework to propose a model of body function, activities and participation, and environment related factors that contribute to work ability. The findings of this scoping review indicate that greater depth of information from a meaning perspective also needs consideration. Models based on ICF might usefully be extended to take account of meaning as an influence on work participation, which in turn could encourage development and use of tools to further explore work meanings in SCI rehabilitation research. These scoping review findings also have important practice implications for clinicians working with people with SCI. Given SCI rehabilitation programs emphasise a patient centred and goal oriented approach in which the patient plays a central role [38]; the findings could be used by clinicians to guide exploration of the meanings of work with patients in SCI rehabilitation and to enhance patient centred goal-setting related to work. This may also be useful in introducing the idea of return to work to patients earlier in inpatient rehabilitation, which other recent studies have suggested as having potential for enhancing post-injury work participation [39, 40].

There are some limitations of this review. First, the search strategy generated a relatively large number of studies, few of which met the criteria for inclusion. This was partly because the search terms related to 'meaning' (see Stage 2) were broad, and identified studies on topics such as quality of life that did not address the scoping review question. Hand searching and citation tracking are used to complement database searches and to enhance the comprehensiveness of scoping reviews. As in a previous related review [18], this approach identified a more substantial number of relevant papers for review, but it cannot be known for certain whether all potentially relevant articles were considered for inclusion. Second, the selection criteria excluded grey literature to focus on published, peerreviewed qualitative evidence, a drawback of which would have been to exclude first-person accounts, narratives and opinions of individuals with SCI. Third, Arksey and O'Malley [19] suggest consultation with consumers and practitioners can enhance scoping reviews. We support this view; indeed, consumer and practitioner views of the meaning of work following SCI are being sought in subsequent research informed by this scoping review. Fourth, the scoping review findings are inevitably limited by the nature of the data reported in the articles. Notably, most studies involved single interviews with participants, and so did not investigate changes in how participants experienced work or its meanings over time. More studies of a longitudinal nature would be beneficial to identify how the meanings of work may change during job-seeking and whilst working, so as to better understand the barriers and facilitators to sustainable employment [25, 28, 29], how identities are successfully modified through pursing employment post-injury, and how clinicians can support this process [25]. Lastly, often the reviewed studies involved mixed participant groups, meaning that it was not possible to differentiate the meaning of work according to gender. This supports Nolan's view [41] that further investigation of the influence of gender on the work experiences of people with SCI is needed, particularly given men and women with SCI may have differing patterns of workforce participation. Similarly, their type of injury, social or work status may impact the meanings that people with SCI ascribed to work. Therefore, future exploration of these variables is important to more effectively target meaningful vocational interventions.

\section{Conclusion}

This scoping review aimed to explore what is known about the meaning of work after spinal cord injury from the existing research literature. Varied meanings of work were identified, including redeveloping a sense of self, reestablishing a place in the community, and regaining economic self-sufficiency. These findings can guide and support vocational programs to explore ideas about work, why 
and how work may be meaningful with people with SCI, so as to identify individually and contextually relevant work. This review also suggests models of factors contributing to work ability and participation could usefully be extended to take account of the meanings of work, so as to enhance patient centred approaches in SCI rehabilitation.

\section{Compliance with ethical standards}

Conflict of interest The authors declare that they have no competing interests.

\section{References}

1. Lee BB, Cripps RA, Fitzharris M, Wing PC. The global map for traumatic spinal cord injury epidemiology: update 2011, global incidence rate. Spinal Cord. 2014;52:110-6.

2. Ackery A, Tator C, Krassioukov A. A global perspective on spinal cord injury epidemiology. J Neurotrauma. 2004;21:1355-1370

3. Singh A, Tetreault L, Kalsi-Ryan S, Nouri A, Fehlings MG. Global prevalence and incidence of traumatic spinal cord injury. Clin Epidemiol. 2014;6:309-31.

4. Ottomanelli L, Lind L. Review of critical factors related to employment after spinal cord injury: implications for research and vocational services. J Spinal Cord Med. 2009;32:503-31

5. Post MW, van Leeuwen CM. Psychosocial issues in spinal cord injury: a review. Spinal Cord. 2012;50:382-9.

6. Ramakrishnan K, Loh SY, Omar Z. Earnings among people with spinal cord injury. Spinal Cord. 2011;49:986-9.

7. Krause JS, Saunders LL, Acuna J. Gainful employment and risk of mortality after spinal cord injury: effects beyond that of demographic, injury and socioeconomic factors. Spinal Cord. 2012;50:784-8.

8. Burns SM, Boyd BL, Hill J, Hough S. Psychosocial predictors of employment status among men living with spinal cord injury. Rehabil Psychol. 2010;55:81-90.

9. Lidal IB, Tuan Khai H, Biering-Sørensen F. Return to work following spinal cord injury: a review. Disabil Rehabil. 2007;29:1341-75.

10. Young AE, Murphy GC. Employment status after spinal cord injury (1992-2005): a review with implications for interpretation, evaluation, further research, and clinical practice. Int J Rehabil Res. 2009;32:1-11.

11. Yasuda S, Wehman P, Targett P, Cifu DX, West M. Return to work after spinal cord injury: a review of recent research. NeuroRehabil. 2002;17:177-86.

12. Murphy G, Young A, Brown D, King N. Explaining labor force status following spinal cord injury: the contribution of psychological variables. J Rehabil Med. 2003;35:276-83.

13. Kent ML, Dorstyn DS. Psychological variables associated with employment following spinal cord injury: a meta-analysis. Spinal Cord. 2014;52:722-8.

14. Reinhardt JD. Post MWM disability: social and psychological aspects. In: James D Wright, editor. International encyclopedia of the social and behavioral sciences. 6.2 ed. Oxford: Elsevier, 2015, pp 467-71.

15. Hammell KW. Quality of life after spinal cord injury: a metasynthesis of qualitative findings. Spinal Cord. 2007;45:124-39.

16. Hammell KW. Exploring quality of life following high spinal cord injury: a review and critique. Spinal Cord. 2004;42:491-502.
17. Hammell KW. Dimensions of meaning in the occupations of daily life. Can J Occup Ther. 2004;71:296-305.

18. Saunders SL, Nedelec B. What work means to people with work disability: a scoping review. J Occup Rehabil. 2014;24:100-10.

19. Arksey H, O'Malley L. Scoping studies: towards a methodological framework. Int J Soc Res Method. 2005;8:19-32

20. Trenaman LM, Miller WC, Escorpizo R. The SRT interventions for improving employment outcomes among individuals with spinal cord injury: a systematic review. Spinal Cord. 2014;52:788-94.

21. Angel S, Kirkevold M, Pedersen BD. Getting on with life following a spinal cord injury: regaining meaning through six phases. Int J Qualit Studies Health Well-being. 2009;4:39-50.

22. Boswell BB, Dawson M, Heininger E. Quality of life as defined by adults with spinal cord injuries. J Rehabil. 1998;64:27-32.

23. Chapin MH, Kewman DG. Factors affecting employment following spinal cord injury: a qualitative study. Rehabil Psychol. 2001;46:400-16.

24. Hammell KW. Quality of life among people with high spinal cord injury living in the community. Spinal Cord. 2004:42:607-20.

25. Hay-Smith EJC, Dickson B, Nunnerley J, Anne Sinnott K. 'The final piece of the puzzle to fit in': an interpretative phenomenological analysis of the return to employment in New Zealand after spinal cord injury. Disabil Rehabil. 2013;35:1436-46.

26. Leiulfsrud AS, Reinhardt JD, Ostermann A, Ruoranen K, Post MWM. The value of employment for people living with spinal cord injury in Norway. Disabil Soc. 2014;29:1177-91.

27. Boschen KA, Tonack M, Gargaro J. Long-term adjustment and community reintegration following spinal cord injury. Int $\mathrm{J}$ Rehabil Res. 2003;26:157-64.

28. Bergmark L, Westgren N, Asaba E. Returning to work after spinal cord injury: exploring young adults' early expectations and experience. Disabil Rehabil. 2011;33:2553-58.

29. Chan SKK, Man DWK. Barriers to returning to work for people with spinal cord injuries: a focus group study. Work. 2005;25:325-32.

30. Fadyl JK, McPherson KM. Understanding decisions about work after spinal cord injury. J Occup Rehabil. 2010;20:69-80.

31. Manns PJ, Chad KE. Components of quality of life for persons with a quadriplegic and paraplegic spinal cord injury. Qual Health Res. 2001;11:795-811.

32. Weitzner E, Surca S, Wiese S, Dion A, Roussos Z, Renwick R, et al. Getting on with life: positive experiences of living with a spinal cord injury. Qual Health Res. 2011;21:1455-68.

33. Wilbanks SR, Ivankova NV. Exploring factors facilitating adults with spinal cord injury rejoining the workforce: a pilot study. Disabil Rehabil. 2015;37:739-49.

34. Fossey E, Harvey C, McDermott F, Davidson L. Understanding and evaluating qualitative research*. Austr New Zealand J Psychiatr. 2002;36:717-32.

35. Hairault JO, Sopraseuth T, Langot F. Distance to retirement and older workers 'employment: The case for delaying the retirement age. J Eur Econ Assoc. 2010;8:1034-76.

36. Marti A, Reinhardt JD, Graf S, Escorpizo R, Post MWM. To work or not to work: labour market participation of people with spinal cord injury living in Switzerland. Spinal Cord. 2012;50:521-6.

37. Fadyl JK, McPherson KM, Schluter PJ, Turner-Stokes L. Factors contributing to work-ability for injured workers: literature review and comparison with available measures. Disabil Rehabil. 2010;32:1173-83.

38. International Spinal Cord Society (ISCoS). Team-based care roles \& responsibilities - Overview: eLearnSCI.org; 2012; http:// www.elearnsci.org/downloads/152_3.pdf. 
39. Middleton JW, Johnston D, Murphy G, Ramakrishnan K, Savage N, Harper R, et al. Early access to vocational rehabilitation for spinal cord injury inpatients. J Rehabil Med. 2015;47:626-31.

40. Ramakrishnan K, Johnston D, Garth B, Murphy G, Middleton J, Cameron I. Early access to vocational rehabilitation for inpatients with spinal cord injury: a qualitative study of patients' perceptions. Topics in spinal cord injury. Rehabilitation. 2016;22:183-91.

41. Nolan M. Masculinity lost: a systematic review of qualitative research on men with spinal cord injury. Spinal Cord. 2013;51:588-95. 